\title{
Pengujian Black Box pada Aplikasi Sistem Pengarsipan Surat Menggunakan Teknik Equivalence Partitions
}

\author{
Handy Nur ${ }^{1}$, Ihda Setiaji Nugroho ${ }^{2}$, Muhammad Rizki Eka Saputra ${ }^{3}$, Nanang Suhaemi ${ }^{4}$, \\ Aries Saifudin 5
}

Teknik Informatika, Universitas Pamulang, Tangerang Selatan, Indonesia e-mail: '1handynur66@gmail.com, ${ }^{2}$ ihdasetiajidsc@ gmail.com, ${ }^{3}$ mrizkiekasaputra@gmail.com,

${ }^{4}$ nanang.suhaemi@gmail.com, ${ }^{5}$ aries.saifudin@unpam.ac.id

Submitted Date: March $21^{\text {st }}, 2020$

Revised Date: April 07 ${ }^{\text {th }}, 2020$
Reviewed Date: April 05 $5^{\text {th }}, 2020$

Accepted Date: April $29^{\text {th }}, 2020$

\begin{abstract}
Archiving is usually carried out by the secretary or administration. The archive manager usually does it manually, it makes the number of archives stored and looks increasingly unorganized on the filing shelf. As a result, the archiving section will need a lot of time to search for documents that have long been stored. Especially in the modern era, the development of increasingly sophisticated technology will help the archiving in managing the records in the room or office. One of them is through software testing or software testing, this device is one of the software tools used to obtain information or results on the quality of a product and service application. This test in addition to looking for errors or defects of an application also has other functions, such as testing how far the capabilities of the application or system. Equivalence Partitions Technique is a test based on entering data in 2 (two) forms in a letter archive application, each menu input will be tested and grouped according to function whether it is true or false. So expect the quality of the software produced in accordance with the expected function.
\end{abstract}

Keywords: Applications, Testing, Black Box, Equivalence Partitions, Letter Archives.

\section{Abstrak}

Pengarsipan biasanya dilakukan oleh bagian sekretaris atau bagian administrasi. Pengelola arsip biasanya melakukan secara manual, hal itu membuat banyaknya arsip yang tersimpan dan terlihat semakin tidak tertata rapih di rak pengarsipan. Akibatnya, bagian pengarsipan akan membutuhkan banyak waktu untuk mencari dokumen yang telah lama tersimpan. Terutama di era modern, perkembangan teknologi yang semakin canggih akan membantu bagian pengarsipan dalam menata arsip yang ada di ruangan atau kantor. Salah satunya melalui pengujian perangkat lunak atau software testing, perangkat ini merupakan salah satu alat perangkat lunak yang digunakan untuk mendapatkan keterangan atau hasil terhadap mutu dari suatu produk dan layanan aplikasi tersebut. Pengujian ini selain untuk mencari kesalahan atau cacat dari suatu aplikasi juga memiliki fungsi lain, seperti menguji seberapa jauh kemampuan dari aplikasi atau sistem tersebut. Teknik Equivalence Partitions merupakan sebuah pengujian berdasarkan masukkan data pada 2 (dua) form yang ada pada aplikasi arsip surat, setiap menu masukan akan dilakukan pengujian dan dikelompokkan berdasarkan fungsinya baik itu bernilai benar ataupun salah. Sehingga diharapkan kualitas software yang dihasilkan sesuai dengan fungsi yang diharapkan.

Kata Kunci: Aplikasi, Pengujian, Black Box, Equivalence Partitions, Arsip Surat.

\section{Pendahuluan}

Surat adalah alat atau sarana komunikasi yang baik dalam bentuk tulisan maupun gambar yang digunakan oleh pihak-pihak terkait seperti perusahaan, organisasi, maupun pribadi kepada pihak lain untuk menyampaikan suatu informasi yang berfungsi sebagai bukti konkrit pada suatu hal atau kejadian tertentu (Suherman, 2017).

Arsip merupakan salah satu produk pekerjaan kantor (office work) selain surat, 
formulir dan laporan (Farell, Saputra, \& Novid, 2018). Umumnya, pengarsipan dilakukan secara manual oleh sekretaris atau bagian administrasi. Hal tersebut membuat sistem pengarsipan di kantor atau instansi terlihat tidak tertata dengan rapih. Terutama di era modern, kini masih banyak beberapa perusahaan atau instansi yang tidak mengenal dan menerapkan sistem pengarsipan. Padahal, sistem pengarsipan memiliki salah satu fungsi guna membuat dokumen dan surat menyurat terususun dengan rapih dan tertata. Seiring dengan perkembangan teknologi di bidang komputer, manusia berlomba-lomba menciptakan teknologi terbaru di bidang komputer, baik berupa perangkat keras (hardware) maupun perangkat lunak (software) yang disebut sebagai aplikasi. (Muludi, Irawati, \& Sari, 2015).

Sistem pengarsipan ini tidak lepas dari pengujian perangkat lunak, karena dengan pengujian perangkat lunak ini sistem akan diuji seberapa jauh sistem berkontribusi untuk memenuhi kebutuhan dalam pengarsipan dokumen-dukumen untuk jangka waktu kedepan (Hidayat \& Muttaqin, 2018).

Sethi pada (Ningrum, Suherman, Aryanti , Prasetya, \& Saifudin, 2019) menjelaskan pengujian pada sebuah program penting untuk dilakukan guna memeriksa semua kesalahan yang ada pada program tersebut agar tidak terjadi kerugian yang akan ditimbulkan dari kesalahan tersebut, sehingga sangat perlu untuk dilakukan pengujian untuk mengurangi terjadinya kesalahan yang merugikan tersebut

Pengujian sistem ini kita berfokus terhadap menu penamabahan arsip surat dalam sistem tersebut, yang kita bertujuan menguji fungsi dari bagian-bagian yang tersedia pada menu didalamnya.

Menu penambahan ini sangat vital fungsinya terhadap keberlangsungan sistem yang berjalan, karena jika terjadi kesalahan pada saat penginputan atau kesalahan dari sistem akan berakibat kesalahan terhadap arsip yang disimpan.

Berdasarkan dari observasi yang dilakukan dalam mengagendakan surat masih menggunakan cara yang manual yang cenderung memakan waktu dalam pencatatan dan memakan waktu dalam pencarian data yang dapat merugikan khususnya bagi perusahaan (Ricat, Zuhri, Budi, Ziasyifa, \& Saifudin, 2020). Dari permasalahan yang ada dibutuhkan sebuah aplikasi sistem pengarsipan surat yang diharapkan dengan adanya aplikasi tersebut akan dapat memberikan keuntungan bagi perusahaan. Program yang akan dibuat pada pengkajian ini adalah program sistem aplikasi pengarsipan surat adalah Black Box Testing, ada beberapa cara dalam menguji Black Box Testing salah satunya adalah mengunakan teknik Equivalence Partitions merupakan sebuah pengujian berdasarkan masukkan data pada setiap form yang ada pada sistem pengarsipan surat terbaik, setiap menu masukan akan dilakukan pengujian dan dikelompokkan berdasarkan fungsinya baik itu bernilai valid ataupun tidak valid (Kurnia, Anie, \& Eva, 2015).

\section{Metodologi}

Pengujian aplikasi bertujuan untuk mengetahui apakah aplikasi sudah sesuai dengan keinginan dan siap untuk digunakan. Metode Black Box Testing adalah sebuah metode yang dipakai untuk menguji sebuah software tanpa harus memperhatikan detail software. Pengujian ini hanya memeriksa nilai keluaran berdasarkan nilai masukan masing-masing. (Hanifah, Alit, \& Sugiarto, 2016). Menurut Roohullah pada (Jaya, 2018) Black Box Testing merupakan Teknik pengujian perangkat lunak yang berfokus pada spesifikasi fungsional dari perangkat lunak. Tidak ada upaya untuk mengetahui kode program apa yang output pakai. Proses Black Box Testing dengan cara mencoba program yang telah dibuat dengan mencoba memasukkan data pada setiap formnya. Pengujian ini diperlukan untuk mengetahui program tersebut berjalan sesuai dengan yang dibutuhkan oleh perusahaan. Salah satu jenis pengujian Black Box Testing adalah dengan menggunakan teknik Equivalence Partitioning (EP) yang penulis gunakan untuk menguji masukan serta membagi masukan kedalam kelompok-kelompok berdasarkan fungsinya. Sehingga didapatkan sebuah test case yang akurat. Dalam penelitian ini akan dilakukan beberapa tahapan. Pada tahapan pertama diawali dengan menentukan Test Case sistem dengan menggunakan metode Equivalence Partitions (MZ, 2016). 

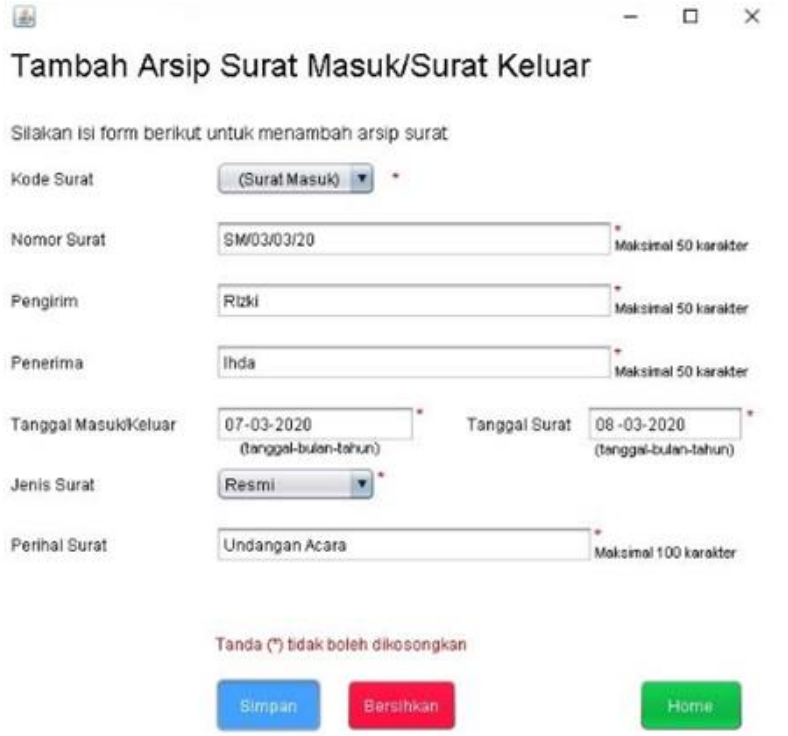

Gambar 1 Tampilan Form Tambah Arsip Surat Masuk/Keluar

Pengujian ini dilakukan pada Form Tambah Arsip Surat Masuk/Keluar dengan memasukkan data yang tidak sesuai dengan type data. Rencana pengujian Kode Surat harus dipilih salah satu data pada combobox tersebut dan tidak boleh kosong. Pada rencana pengujian Nomor Surat data akan valid jika Nomor Surat diisi dengan memasukkan angka, huruf dan simbol dengan batas maksimal 50 karakter dan tidak boleh kosong, sebaliknya data tidak akan valid jika Nomor Surat diisi melebihi 50 karakter. Pada rencana pengujian Pengirim data akan valid jika Pengirim diisi dengan memasukkan angka, huruf dan simbol dengan batas maksimal 50 karakter dan tidak boleh kosong, sebaliknya data tidak akan valid jika Pengirim diisi melebihi 50 karakter. Pada rencana pengujian Penerima data akan valid jika Penerima diisi dengan memasukkan angka, huruf dan simbol dengan batas maksimal 50 karakter dan tidak boleh kosong, sebaliknya data tidak akan valid jika Penerima diisi melebihi 50 karakter. Pada rencana pengujian Tanggal Masuk/Keluar data akan valid jika Tanggal Masuk/Keluar hanya diisi dengan angka dengan simbol penghubung minus(-), sebaliknya data tidak akan valid jika Tanggal Masuk/Keluar diisi dengan huruf. Pada rencana pengujian Tanggal Surat data akan valid jika Tanggal Surat hanya diisi dengan angka dengan simbol penghubung minus(-), sebaliknya data tidak akan valid jika Tanggal Surat diisi dengan huruf. Pada rencana Jenis Surat harus dipilih salah satu data pada combobox tersebut dan tidak boleh kosong. Pada rencana Perihal Surat data akan valid jika diisi dengan angka, huruf, dan simbol dengan batas maksimal 100 karakter, sebaliknya data tidak akan valid jika Perihal Surat diisi melebihi 100 karakter.

Tabel 1 Rancangan Test Case Form Arsip Surat Masuk/Keluar

\begin{tabular}{|c|c|c|}
\hline ID & Deskripsi Pengujian & Hasil yang diharapkan \\
\hline P01 & $\begin{array}{l}\text { Memilih combobox Kode Surat "Surat Masuk", Nomor } \\
\text { Surat diisi dengan "SM/03/03/2020", Pengirim diisi dengan } \\
\text { "Rizki", Penerima diisi dengan "Ihda", Tanggal } \\
\text { Masuk/Keluar diisi dengan "07-03-2020", Tanggal Surat } \\
\text { diisi dengan "08-03-2020", memilih combobox Jenis Surat } \\
\text { "Resmi", Perihal Surat diisi dengan "Undangan Acara", } \\
\text { kemudian klik tombol Simpan. }\end{array}$ & $\begin{array}{l}\text { Data akan tersimpan ke } \\
\text { database dan akan } \\
\text { tampil di tabel menu } \\
\text { Arsip Surat. }\end{array}$ \\
\hline P02 & $\begin{array}{l}\text { Memilih combobox Kode Surat "Surat Masuk", Nomor } \\
\text { Surat diisi dengan "SM/03/03/2020", Pengirim diisi dengan } \\
\text { "Rizki", Penerima diisi dengan "Ihda", Tanggal } \\
\text { Masuk/Keluar diisi dengan "07-Maret-2020", Tanggal Surat } \\
\text { diisi dengan "08-Maret-2020", memilih combobox Jenis } \\
\text { Surat "Resmi", Perihal Surat diisi dengan "Undangan } \\
\text { Acara", kemudian klik tombol Simpan. }\end{array}$ & $\begin{array}{l}\text { Aplikasi akan menolak } \\
\text { untuk menyimpan dan } \\
\text { akan menampilkan } \\
\text { pesan input salah. }\end{array}$ \\
\hline
\end{tabular}


(-9) Aplikasi Arsip Surat

Tambah Arsip Memo

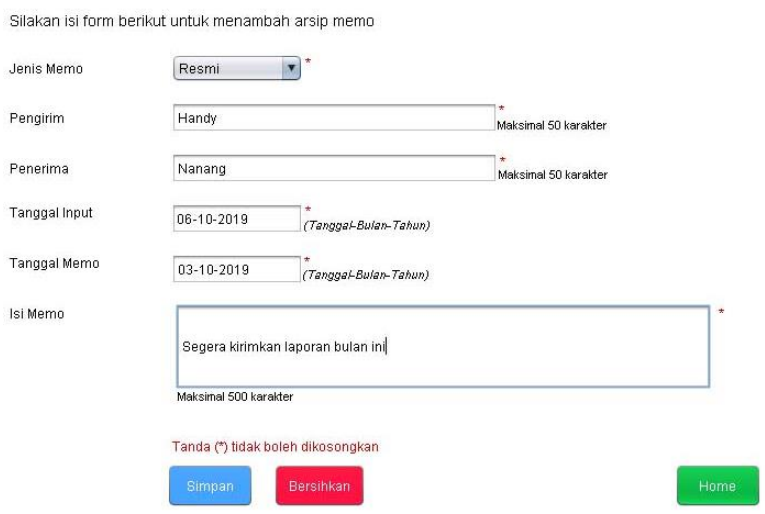

Gambar 2 Form Tambah Arsip Memo

Pengujian berikutnya dilakukan pada Form Tambah Arsip Memo dengan memasukkan data yang tidak sesuai dengan type data. Pada rencana pengujian Jenis Memo harus dipilih salah satu data pada combobox dan tidak boleh kosong. Pada rencana pengujian Pengirim data akan valid jika Pengirim diisi dengan memasukkan angka, huruf dan simbol dengan batas maksimal 50 karakter dan tidak boleh kosong, sebaliknya data tidak akan valid jika Pengirim diisi melebihi 50 karakter. Pada rencana pengujian Penerima data akan valid jika Penerima diisi dengan memasukkan angka, huruf dan simbol dengan batas maksimal 50 karakter dan tidak boleh kosong, sebaliknya data tidak akan valid jika Penerima diisi melebihi 50 karakter. Pada rencana pengujian Tanggal Input data akan valid jika Tanggal Input hanya diisi dengan memasukkan angka dengan simbol penghubung minus(-), sebaliknya data tidak akan valid jika Tanggal Input diisi dengan memasukkan huruf. Pada rencana pengujian Tanggal Memo data akan valid jika Tanggal Memo hanya diisi dengan memasukkan angka dengan simbol penghubung minus(-), sebaliknya data tidak akan valid jika Tanggal Memo diisi dengan memasukkan huruf. Pada rencana Isi Memo data akan valid jika Isi Memo diisi dengan memasukkan huruf, angka, dan simbol dengan batas maksimal 500 karakter, sebaliknya data tidak akan valid jika Isi Memo diisi melebihi 500 karakter.

Tabel 2 Rancangan Test Case form Arsip Memo

\begin{tabular}{|l|l|l|}
\hline ID & Deskripsi Pengujian & Hasil yang diharapkan \\
\hline M01 & $\begin{array}{l}\text { Memilih combobox Jenis Memo "Resmi", Pengirim diisi } \\
\text { dengan "Handy", Penerima diisi dengan "Nanang", Tanggal }\end{array}$ & $\begin{array}{l}\text { Data akan tersimpan ke } \\
\text { database dan tampil di } \\
\text { Input diisi dengan "06-10-2019", Tanggal Memo diisi dengan } \\
\text { "03-10-2019", Isi Memo diisi dengan "Segera kirimkan } \\
\text { laporan bulan ini", kemudian klik tombol Simpan. }\end{array}$ \\
\hline M02 & $\begin{array}{l}\text { Memilih combobox Jenis Memo "Resmi", Pengirim diisi } \\
\text { dengan "Handy", Penerima diisi dengan "Nanang", Tanggal } \\
\text { Input diisi dengan "06-Oktober-2019", Tanggal Memo diisi } \\
\text { dengan "03-Oktober-2019", Isi Memo diisi dengan "Segera } \\
\text { kirimkan laporan bulan ini", kemudian klik tombol Simpan. }\end{array}$ & $\begin{array}{l}\text { Aplikasi akan menolak } \\
\text { untuk menyimpan dan } \\
\text { akan menampilkan pesan } \\
\text { input salah. }\end{array}$ \\
\hline
\end{tabular}

\section{Hasil dan Pembahasan}

Berdasarkan rancangan test case pada Tabel

1 dan 2, maka dapat dibuat hasil pengujian yang ditunjukkan pada Tabel 3.

Tabel 3 Hasil Pengujian

\begin{tabular}{|l|l|l|l|l|}
\hline ID & Deskripsi Pengujian & $\begin{array}{l}\text { Hasil yang } \\
\text { diharapkan }\end{array}$ & $\begin{array}{l}\text { Hasil } \\
\text { Pengujian }\end{array}$ & Kesimpulan \\
\hline P01 & Memilih combobox Kode Surat "Surat Masuk", & $\begin{array}{l}\text { Data akan } \\
\text { tersimpan ke }\end{array}$ & $\begin{array}{l}\text { Data akan } \\
\text { tersimpan ke }\end{array}$ & Sesuai \\
& Nomor Surat diisi dengan "SM/03/03/2020", & \\
& $\begin{array}{l}\text { Pengirim diisi dengan "Rizki", Penerima diisi } \\
\text { database dan } \\
\text { database dan }\end{array}$ & \\
& dengan "Ihda", Tanggal Masuk/Keluar diisi & akan tampil & akan tampil & \\
dengan "07-03-2020", Tanggal Surat diisi & di tabel menu & di tabel menu & \\
\hline
\end{tabular}




\begin{tabular}{|c|c|c|c|c|}
\hline & $\begin{array}{l}\text { dengan "08-03-2020", memilih combobox Jenis } \\
\text { Surat "Resmi", Perihal Surat diisi dengan } \\
\text { "Undangan Acara", kemudian klik tombol } \\
\text { Simpan. }\end{array}$ & Arsip Surat. & Arsip Surat. & \\
\hline $\mathrm{P} 02$ & $\begin{array}{l}\text { Memilih combobox Kode Surat "Surat Masuk", } \\
\text { Nomor Surat diisi dengan "SM/03/03/2020", } \\
\text { Pengirim diisi dengan "Rizki", Penerima diisi } \\
\text { dengan "Ihda", Tanggal Masuk/Keluar diisi } \\
\text { dengan "07-Maret-2020", Tanggal Surat diisi } \\
\text { dengan "08-Maret-2020", memilih combobox } \\
\text { Jenis Surat "Resmi", Perihal Surat diisi dengan } \\
\text { "Undangan Acara", kemudian klik tombol } \\
\text { Simpan. }\end{array}$ & $\begin{array}{l}\text { Aplikasi } \\
\text { akan } \\
\text { menolak } \\
\text { untuk } \\
\text { menyimpan } \\
\text { dan akan } \\
\text { menampilkan } \\
\text { pesan input } \\
\text { salah. }\end{array}$ & $\begin{array}{l}\text { Aplikasi } \\
\text { akan } \\
\text { menolak } \\
\text { untuk } \\
\text { menyimpan } \\
\text { dan akan } \\
\text { menampilkan } \\
\text { pesan input } \\
\text { salah. }\end{array}$ & Sesuai \\
\hline M01 & $\begin{array}{l}\text { Memilih combobox Jenis Memo "Resmi", } \\
\text { Pengirim diisi dengan "Handy", Penerima diisi } \\
\text { dengan "Nanang", Tanggal Input diisi dengan } \\
\text { "06-10-2019", Tanggal Memo diisi dengan "03- } \\
\text { 10-2019", Isi Memo diisi dengan "Segera } \\
\text { kirimkan laporan bulan ini", kemudian klik } \\
\text { tombol Simpan. }\end{array}$ & $\begin{array}{l}\text { Data akan } \\
\text { tersimpan ke } \\
\text { database dan } \\
\text { tampil di } \\
\text { tabel menu } \\
\text { Memo. }\end{array}$ & $\begin{array}{l}\text { Data akan } \\
\text { tersimpan ke } \\
\text { database dan } \\
\text { tampil di } \\
\text { tabel menu } \\
\text { Memo. }\end{array}$ & Sesuai \\
\hline M02 & $\begin{array}{l}\text { Memilih combobox Jenis Memo "Resmi", } \\
\text { Pengirim diisi dengan "Handy", Penerima diisi } \\
\text { dengan "Nanang", Tanggal Input diisi dengan } \\
\text { "06-Oktober-2019", Tanggal Memo diisi dengan } \\
\text { "03-Oktober-2019", Isi Memo diisi dengan } \\
\text { "Segera kirimkan laporan bulan ini", kemudian } \\
\text { klik tombol Simpan. }\end{array}$ & $\begin{array}{l}\text { Aplikasi } \\
\text { akan } \\
\text { menolak } \\
\text { untuk } \\
\text { menyimpan } \\
\text { dan akan } \\
\text { menampilkan } \\
\text { pesan input } \\
\text { salah. }\end{array}$ & $\begin{array}{l}\text { Aplikasi } \\
\text { akan } \\
\text { menolak } \\
\text { untuk } \\
\text { menyimpan } \\
\text { dan akan } \\
\text { menampilkan } \\
\text { pesan input } \\
\text { salah. }\end{array}$ & Sesuai \\
\hline
\end{tabular}

\section{Kesimpulan}

Pengujian aplikasi dengan Blackbox Testing bertujuan melihat program tersebut sama dengan tugas atau fungsi pada program tanpa mengetahui sumber kode program yang dipakai. Dapat ditarik kesimpulan bahwa pengujian dengan menggunakan metode Blackbox dengan Teknik Equivalence Partitions dapat membantu menemukan kesalahan pada sistem yang sudah dibuat sebelum sistem digunakan.

\section{Saran}

Saran agar aplikasi berikutnya dapat menjadi lebih baik, yaitu menggunakan teknik pengujian Blackbox Testing lainnya seperti Boundary Value atau Error Guessing agar kita dapat menemukan kesalahan/error yang lebih luas pada pengembangan aplikasi ini.

\section{Referensi}

Farell, G., Saputra, H. K., \& Novid, I. (2018). Rancang Bangun Sistem Informasi Pengarsipan Surat
Menyurat (Studi Kasus Fakultas Teknik UNP). Jurnal Teknologi Informasi dan Pendidikan Vol. 11, No. 2, September 2018, 56.

Hanifah, U., Alit, R., \& Sugiarto. (2016). Penggunaan Metode Black Box Pada Pengujian Sistem Informasi Surat Keluar Masuk. SCAN VOL. XI NOMOR 2 JUNI 2016, 34.

Hidayat, T., \& Muttaqin, M. (2018). Pengujian Sistem Informasi Pendaftaran dan Pembayaran Wisuda Online Menggunakan Black Box Testing dengan Metode Equivalence Partitioning dan Boundary Value Analysis. Jurnal Teknik Informatika UNIS JUTIS, April 2018, Vol. 6 No.1.

Jaya, T. S. (2018). Pengujian Aplikasi dengan Metode Blackbox Testing Boundary Value Analysis (Studi Kasus: Kantor Digital Politeknik Negeri Lampung). Jurnal Pengembangan IT (JPIT), Vol.03, No.02, Januari 2018, 45.

Kurnia, Anie, \& Eva. (2015). Pengembangan Sistem Pengarsipan Surat Di Bidang Sumber Daya Manusia dan Komunikasi Hukum Administrasi (SDM \& KHA) Pada PT PLN 
(Persero) Wilayah Lampung. Jurnal Komputasi, 52.

Muludi, K., Irawati, A. R., \& Sari, E. D. (2015). Pengembangan Sistem Pengarsipan Surat Di Bidang Sumber Daya Manusia dan Komunikasi Hukum Administrasi (SDM \& KHA) Pada PT PLN (Persero) Wilayah Lampung. Jurnal Komputasi Vol. 3, No. 1, 2015, 47-56.

MZ, M. K. (2016). Pengujian Perangkat LunakMetode Black-Box Berbasis Equivalence Partitions Pada Aplikasi Sistem Informasi Sekolah. Jurnal Mikrotik Edisi Bulan Februari 2016, Volume: 06 Nomor: 03, 6.

Ningrum, F. C., Suherman, D., Aryanti , S., Prasetya, H. H., \& Saifudin, A. (2019). Pengujian Black Box pada Aplikasi Sistem Seleksi Sales Terbaik Menggunakan Teknik Equivalence
Partitions. Jurnal Informatika Universitas Pamulang Vol. 4, No. 4, Desember 2019 (125130), 125.

Ricat, A., Zuhri, M., Budi, R., Ziasyifa, \& Saifudin, A. (2020). Pengujian Black Box pada Sistem Aplikasi Informasi Data Kinerja Menggunakan Teknik Equivalence Partitions. Jurnal Teknologi Sistem Informasi dan Aplikasi, $\quad 3(1), \quad 9-14$. doi:10.32493/jtsi.v3i1.4303

Suherman, Y. (2017). Sistem Informasi Kearsipan Tata Kelola Surat Pada Kantor Inspeksi BRI Kota Padang. jurnal Rekayasa Sistem dan Teknologi Informasi Vol. 1 No. 1 (2017) 26 33, 27. 